\title{
ARQUITETURA ESCOLAR E DESIGUALDADE ÉTNICO-RACIAL (RELATO DE EXPERIÊNCIA)
}

Rachel de Oliveiral

Resumo: Apresentamos neste artigo relatos de experiências que retratam as condições dos espaços físicos das escolas de Educação Infantil do município de Ilhéus, na Bahia. Nosso principal objetivo tem sido analisar se tais recintos atendem as orientações contidas nos Parâmetros Básicos de Infra-estrutura para as Instituições de Educação Infantil e nos Parâmetros Nacionais de Qualidade para a Educação Infantil, ambos publicados em 2006. No desenvolvimento desse processo, utilizamos os fundamentos da pesquisa-intervenção, uma metodologia que analisa e questiona as relações de poder institucionais. Nessa perspectiva, discutimos a possibilidade de existirem conexões entre arquitetura escolar, condição social dos usuários e a variável cor/etnia. Os resultados indicam que as escolas, notadamente as construídas nas periferias da cidade, estão historicamente alicerçadas no contínuo processo de preservação das desigualdades étnico-raciais e educacionais.

Palavras-chave: Arquitetura Escolar; Desigualdade Regional; Desigualdade Étnico-racial.

\section{SCHOOL ARCHITECTURE AND ETHNIC-RACIAL INEQUALITY}

\begin{abstract}
We Present in this article reports of experiences that reflect the conditions of the physical spaces of Children's Education schools in the city of Ilhéus, Bahia. Our main objective has been to analyse whether such enclosures meet the guidelines contained in Basic Parameters Dand Infra-Structure For as InstI dand early Childhood Education and US National Quality Parameters For a Early Childhood Education, both published in 2006. In the development of this process, we use the fundamentals of intervention research, a methodology that analyzes and questions institutional power relations. In this perspective, Discuss The possibility of there being connections between school architecture, social condition of users and the variable color/ethnicity. The results indicate that schools, notably those built on the outskirts of the city, are historically grounded in the continuous process of preserving ethnic-racial and educational inequalities.
\end{abstract}

Key-words: School Architecture; Regional Inequality; Ethnic-racial Inequality.

\section{L'ARCHITECTURE SCOLAIRE ET L'INÉGALITÉ ETHNIQUE-RACIALE}

Résumé: Nous présentons dans cet article des rapports d'expériences qui reflètent les conditions des espaces physiques des écoles d'éducation des enfants dans la ville d'Ilhéus, Bahia. Notre objectif principal a été d'analyser si ces boîtiers satisfont aux directives contenues dans Paramètres de base Det infra-Structure Foras instituições det l'éducation de la petite enfance et aux États-Unis Paramètres nationaux de qualité Fora Éducation de la petite enfance, tous deux publiés en 2006. Dans l'élaboration de ce processus, nous utilisons les fondements de la recherche interventionnelle, une méthodologie qui analyse et interroge les relations de pouvoir institutionnelles. Dans cette perspective, discuter la possibilité d'y avoir des connexions entre l'architecture de l'école, la condition sociale des utilisateurs et la variable couleur/ethnicité. Les résultats indiquent que les écoles, notamment celles construites à la périphérie de la ville, sont

\footnotetext{
${ }^{1}$ Professora titular do Departamento de Ciências da Educação da Universidade Estadual de Santa Cruz (UESC). Coordenadora do Projeto Educação e Multiculturalismo - formação para a Diversidade Cultural. E-mail: rakkadeoliveira@gmail.com
} 
historiquement ancrées dans le processus continu de préservation des inégalités ethniquesraciales et éducatives.

Mots-clés: L’architecture de l'école; Inégalités régionales; Inégalité ethnique-raciale.

\section{ARQUITECTURA ESCOLAR Y DESIGUALDAD ÉTNICO-RACIAL}

Resumen: Presentamos en este artículo informes de experiencias que reflejan las condiciones de los espacios físicos de las escuelas de educación infantil en la ciudad de Ilhéus, Bahía. Nuestro principal objetivo ha sido analizar si dichos recintos cumplen las directrices contenidas en Parámetros básicos De infra-Estructura para as instI dy educación infantil temprana y Estados Unidos Parámetros nacionales de calidad para a Educación infantil temprana, ambos publicados en 2006. En el desarrollo de este proceso, utilizamos los fundamentos de la investigación de la intervención, una metodología que analiza y cuestiona las relaciones de poder institucional. En esta perspectiva, discutimos La posibilidad de que existan conexiones entre la arquitectura de la escuela, la condición social de los usuarios y el color/etnia variable. Los resultados indican que las escuelas, en particular las construidas en las afueras de la ciudad, están históricamente fundamentadas en el proceso continuo de preservación de las desigualdades étnicas-raciales y educativas.

Palabras-clave: Arquitectura de la escuela; Desigualdad regional; La desigualdad racial étnica.

\section{INTRODUÇÃO}

Optei por introduzir o debate sobre "Arquitetura Escolar e Desigualdades Étnico-racial e Regional" como tema a ser apresentado no seminário intitulado "Raça negra e educação 30 anos depois. E agora do que mais precisamos falar”?

Nesse espaço de tempo, o Movimento Social Negro avançou no debate contra a discriminação racial, atingindo positivamente diferentes áreas do conhecimento, com destaque para o Direito, a Educação, questões relacionadas ao gênero e à juventude, entre outras; entretanto, por falta de políticas públicas para a concretização dessas ações, talvez a população negra continue com as mesmas necessidades que foram apontadas nas três décadas anteriores. Por essa razão, na atual conjuntura, temos muitas dificuldades para escolher o que falar, considerando a infinidade de problemas a serem enfrentados, a exemplo da intolerância religiosa, o desemprego e o assassinato dos jovens negros, uma séria questão que vimos tentando solucionar desde 1978, ano de criação do Movimento Negro Unificado $(\mathrm{MNU})^{2}$. Conforme o Índice de Vulnerabilidade Juvenil à Violência e Desigualdade Racial 2014 (Brasil, 2015, p. 21,

\footnotetext{
${ }^{2}$ Uma das principais reivindicações do Movimento Negro Unificado, criado em 1978, era a luta contra a violência policial, que atingia mortalmente os jovens negros.
} 
grifos nossos), "a prevalência de jovens negros serem mais vítimas de assassinatos do que jovens brancos é uma tendência nacional”. O genocídio de jovens negros tem sido um fenômeno assustador e sem qualquer mecanismo social de controle.

Afirmamos, veementemente, que não é uma mera tendência, mas uma opção do Estado brasileiro, desde a abolição, quando optou pelo Projeto Imigrantista ${ }^{3}$, que estimulou o preconceito étnico-racial aliado à desigualdade econômica, visando a favorecer a inserção da população branca nos setores mais avançados, enquanto a negra recebeu os mais perversos reflexos dessa combinação, como, por exemplo, a de ser obrigada a frequentar espaços educacionais de baixíssima qualidade, sendo expulsa da escola muito mais cedo que os brancos pobres. Consequentemente, em virtude do total abandono, desde a infância, os jovens negros tornam-se vítimas preferenciais do genocídio, do tráfico de drogas, da violência policial e de outras violências que causam a morte civil.

Uns dos marcos políticos de Cadernos de Pesquisa (1987), n. 63, que completou 30 anos de publicação em 2017, foram as análises das estatísticas educacionais e os debates sobre a mudança curricular. Na ocasião, discutimos dados do Censo de 1980 (Rosemberg et al., 1986) sobre a situação educacional do negro, que revelaram, por exemplo, que, em São Paulo, as crianças brancas das classes menos favorecidas alcançavam, em média, cinco anos de escolaridade, enquanto as crianças negras, pertencentes às mesmas classes, ficavam na escola menos de três anos.

No artigo intitulado "Reflexões sobre a Experiência de Alteração Curricular em São Paulo", publicado em Cadernos de Pesquisa (Oliveira, 1987), ressaltei questões como: a mudança curricular, dando ênfase especial à introdução da História da África, o processo de formação dos professores e a necessidade de os alunos pobres e negros dominarem o denominado conhecimento científico. Argumentei também que o conhecimento elaborado não podia continuar sendo propriedade da burguesia: "Há pessoas, há correntes que são contra o conteúdo; eu sou a favor, acho que os alunos, principalmente das classes populares, precisam de conteúdo, sim, para poder estar em

\footnotetext{
${ }^{3}$ O Projeto denominado Imigrantista foi elaborado, no século XVIII, por políticos e apoiado pela elite brasileira com o objetivo de defender a vinda de imigrantes europeus e dos Estados Unidos para substituir a mão de obra negra.
} 
condições de competir com os demais" (Oliveira, 1987, p. 65). Em nome da Comissão de Educação do Conselho de Participação e Desenvolvimento da Comunidade Negra, destaquei a nossa intervenção nas políticas públicas do estado de São Paulo com o objetivo de pleitear melhorias na construção das escolas ${ }^{4}$.

A precariedade da Rede Física da Escola foi veementemente debatida pela professora Fúlvia Rosemberg et al. (1986), por ter aparecido no "Diagnóstico sobre a Situação Educacional de Negros (Pretos e Pardos) no Estado de São Paulo”. Na época, a pesquisadora afirmou que "a escola frequentada pelo alunado negro não era a mesma frequentada pelo alunado branco" (Rosemberg, 1987, p. 22). Ela também sugeriu, entre outras hipóteses, que o sistema escolar empurraria o alunado negro preferencialmente para equipamentos destinados à população pobre. Nessa perspectiva, recomendou, há 30 anos, que o Movimento Negro reivindicasse, inicialmente, "ao invés de cota, melhores escolas nos bairros com maior quantidade de moradores negros" (Rosemberg, 1987, p. 22-23).

Entretanto, por diferentes motivos, a arquitetura escolar se tornou o centro das minhas preocupações bem mais tarde, em 2007, quando fui lecionar no Nordeste. Talvez minha visão tenha sido ofuscada pelo fato de ter frequentado, durante a minha infância e adolescência, que ocorreu entre as décadas de 1951 e 1970, instituições de educação consideradas padrão, tanto no aspecto pedagógico como no físico. As escolas construídas naquele período foram frutos do processo de urbanização das grandes cidades e da vontade de administradores que lutavam pela modernização do país.

O edifício escolar era considerado um dos pontos altos do processo civilizatório brasileiro, um dos ideais republicanos. Funcionavam como ponto de destaque da cena urbana, portanto era construído em lugar visível, tal como as igrejas (Bencostta, 2001). As escolas que estudei no antigo primário, ginásio e colegial eram muito procuradas, tanto pela chamada excelência dos professores como pelo conforto que escola ofereciam dentro dos padrões da época.

\footnotetext{
4 Naquele momento coordenava a Comissão de Educação do Conselho de Participação e Desenvolvimento da Comunidade Negra.
} 
Quando terminei o curso de Pedagogia, em 1978, trabalhei nessas mesmas escolas e em algumas da periferia da capital de São Paulo, as quais, embora não fossem suntuosas, ofereciam, além das salas de aula, os elementos básicos para um bom funcionamento. Tais instituições eram compostas por salas de professores, sala de leitura, pátio coberto, cozinha, almoxarifado, espaço para merenda e banheiros feminino e masculino.

Em São Paulo, acompanhei três processos importantes da luta para a construção de novos espaços educacionais; a luta das mulheres por creches, na década de 1980; o embate contra as denominadas "Escolas de Latinha", construídas emergencialmente a partir de 1997 e depois substituídas por alvenaria a partir de pressões dos movimentos sociais. Por último, participei do processo de construção dos Centros de Educação Unificado (CEU), do período de 2003 ao final de 2006. Experiência bastante significativa, para mim, pelo fato de poder ver a população empobrecida e marginalizada ter acesso a equipamentos educacionais de qualidade.

Essas experiências causaram-me a falsa impressão de que o empenho pela qualidade dos espaços públicos era um ponto comum e de abrangência nacional, mas, quando mudei de contexto geográfico, do Sudeste para o Nordeste, comecei a compreender o significado das diferenças regionais, para além das leituras dos dados estatísticos, notadamente no campo educacional.

Dentro dessa perspectiva, me interessei pela análise da arquitetura das escolas baianas, destacando os seguintes motivos: primeiro porque, ao observar a arquitetura da cidade, aliada à arquitetura das escolas e a cor da população, pude enxergar estreitos vínculos entre as desigualdades étnico-raciais e as desigualdades regionais. Segundo porque as pesquisas educacionais apontam que as crianças nortistas e nordestinas estão historicamente em desvantagem em relação às que residem na região Sul e Sudeste. O terceiro motivo está vinculado à escassez de estudo sobre a situação de escolas frequentadas pela maioria das crianças negras.

\footnotetext{
5 "Inicialmente, as escolas foram instaladas em conteiners metálicos de zinco ou folha-de-flandres, alegadamente em caráter emergencial, para atender à demanda. Ao todo foram construídas 54 'escolas de lata', durante a administração de Celso Pitta, e nenhuma delas foi substituída até o final da gestão, o que gerou controvérsias quanto ao caráter emergencial da solução". Disponível em: <https://pt.wikipedia.org/wiki/Escolas_de_lata〉. Acesso em: 17 maio 2018.
} 
O cuidado com a arquitetura escolar aparece nas Diretrizes Curriculares Nacionais para a Educação das Relações Étnico-Raciais e para o Ensino de História e Cultura Afro-Brasileira e Africana (DCNERER), no item que se refere às Políticas de Reparações de Reconhecimento e Valorização de Ações Afirmativas: "reconhecer exige que os estabelecimentos de ensino, frequentados em sua maioria pela população negra, contem com instalações e equipamentos sólidos e atualizados” (Brasil, 2004, p. 10).

Estando em Ilhéus, município localizado ao sul da Bahia, na condição de professora do Departamento de Ciências da Educação da Universidade Estadual de Santa Cruz (UESC), retomei a orientação das Diretrizes citada acima e a transformei em tema de pesquisa e de reflexão política.

\section{RECONHECENDO O CONTEXTO}

Ilhéus, chamada terra de Jorge Amado e também Costa de Cacau, tem uma área geográfica de $1.584,693 \mathrm{~km}$ e uma população de 184.236 habitantes; um município turístico que foi muito próspero até o advento da vassoura-de-bruxa ${ }^{6}$, ocorrido em meados de 1990, quando entrou em franca decadência.

Nesse município, por mais de 30 dias, não consegui enxergar sequer uma escola. Por isso tive que perguntar aos colegas onde se encontravam. Na realidade, meus olhos procuravam instituições semelhantes a algumas localizadas nas grandes áreas urbanas. Mas, quando consegui avistá-las, observei que tais instituições não exibiam arquiteturas semelhantes às urbanas, nem características físicas próprias do meio rural ou regional; as configurações espaciais das instituições educacionais ilheenses exibiam uma face antidemocrática que refletia, e ainda reflete, descaso e desigualdade.

Milton Santos (1978, p. 122) argumenta que "o espaço é um verdadeiro campo de forças cuja formação é desigual. Eis a razão pela qual a evolução espacial não se

\footnotetext{
6 “O termo vassoura-de-bruxa é aplicado a um tipo de doença ou sintoma de doença de plantas em que ocorre um desenvolvimento anormal do tecido meristemático ou superbrotamento. Embora a vassoura-debruxa ocorra em muitas espécies de plantas de famílias diferentes e possa ser causado por diversos tipos de patógenos (vírus, fitoplasmas ou fungos), a mais conhecida dentre elas é a que afeta o cacaueiro". Disponível em: 〈https://pt.wikipedia.org/wiki/Vassoura-de-bruxa〉. Acesso em: 26 jul. 2018.
} 
apresenta de igual forma em todos os lugares". Nesta perspectiva, a desqualificação desses espaços não pode ser considerada mera coincidência.

Na década de 1930, o educador Anísio Teixeira, alarmado com as faltas de vagas no antigo Ensino Primário e as péssimas condições dos prédios escolares em todo o Brasil, elaborou um projeto de construção de novas escolas, especialmente para a Bahia, Rio de Janeiro e Distrito Federal. E, ao assumir a Secretaria de Educação e Saúde do Estado da Bahia no período de 1947 a 1951, se esforçou para que a sua terra natal prosperasse via educação pública; para tanto, elaborou um plano de construção de escolas para a capital e para o interior. Alguns opositores de Anísio Teixeira argumentavam que seu projeto de construção de escolas era muito caro, ao que, conforme Tavares (2002, p. 167), ele respondia: “a educação é cara, tem de custar muito dinheiro, porque é somente com a educação que nós podemos construir o Brasil e fazer dele o grande país que todos desejamos".

Salienta Nunes (2001, p. 11) que o grande sonho de Anísio Teixeira era construir

uma escola pública com um Ensino Básico de qualidade para todos, onde a pesquisa é assumida como componente do ensino, e em que os espaços e os tempos da educação sejam significativos para cada sujeito dentro dela. Uma escola bonita, moderna, integral em que o trabalho pedagógico apaixona e compromete professores e alunos. Uma escola que construa um solidário destino humano, histórico e social.

Contrariando o sonho de Anísio Teixeira, as escolas de Educação Infantil que vi em Ilhéus no ano de 2007 funcionavam em casas alugadas, com pouquíssimas condições de acolhimento, incluindo a falta de higiene. Nesse contexto, as crianças eram majoritariamente negras, cerca de $80 \%$, no olhar de alguns professores, mas no meu olhar os não brancos chegavam minimamente a 92\%, entre pretos e pardos e população indígena.

\section{COLOCANDO O TEMA EM EVIDÊNCIA}

A vontade de analisar a arquitetura e a configuração espacial das escolas do município de Ilhéus reacendeu o conflito que parece ser inerente aos pesquisadores/as vinculados aos Movimentos Sociais, que acabam se enveredando para a busca de metodologias participativas e/ou de intervenção como solução para o tratamento dos 
problemas que atingem diferentes comunidades, incluindo a escolar. Por essa razão, fiquei em dúvida entre escolher uma metodologia que pudesse orientar TCC (trabalho de conclusão de curso), IC (iniciação científica) e, ao final da pesquisa, escrever um artigo ou colocar o tema em debate na perspectiva das políticas públicas. A questão não era investigar apenas se as arquiteturas daquelas escolas contrariavam a legislação vigente ou se confirmavam dados estatísticos sobre desigualdades regionais e outras, mas julguei ser importante discutir o assunto com um público mais amplo para que pudéssemos não somente responder à questão de pesquisa, mas também levantar subsídios para futuras intervenções.

Nesse sentido, decidi, inicialmente, introduzir o tema em sala de aula, já que era responsável por duas disciplinas estratégicas - Políticas Públicas Educacionais I e II e História da Educação I e II, no curso de Pedagogia, permanecendo por dois semestres com as mesmas turmas. Para colaborar com o debate sobre a infância, convidei uma professora especialista em Educação Infantil ${ }^{7}$.

Nossa primeira iniciativa foi dialogar com a Secretaria Municipal de Educação de Ilhéus. Na ocasião, elaboramos a proposta de levantar o histórico das instituições de Educação Infantil, analisar a arquitetura escolar e a configuração dos espaços. Porém, neste artigo, não apresentamos a parte que se refere ao levantamento histórico.

Após a aprovação da Secretaria Municipal de Educação, iniciamos um processo de investigação cujo objetivo geral foi o de verificar se as escolas e/ou os espaços de Educação Infantil do município de Ilhéus atendiam às orientações contidas nos Parâmetros Básicos de Infra-estrutura para Instituição de Educação Infantil (Brasil, 2006a) e nos Parâmetros Nacionais de Qualidade para a Educação Infantil (Brasil, 2006b), tendo como objetivos específicos: a) descrever a configuração dos espaços físicos; b) levantar o histórico das instituições vinculadas à Educação Infantil; e c) incluir a análise da arquitetura da escola no processo de formação dos/as discentes de Pedagogia. Nessa perspectiva, interrogamos se existiam conexões entre arquitetura escolar, condição social dos usuários e a variável cor/etnia. E, para a concretização desse processo, utilizamos os seguintes instrumentos: i) um questionário

\footnotetext{
${ }^{7}$ Professora Maria Aparecida D’Ávila Cassimiro.
} 
semiestruturado para dialogarmos com os gestores; ii) a fotografia; iii) a elaboração de croqui; e iv) um roteiro de avaliação dos espaços, tendo como base as legislações sobre a Educação Infantil.

Como já citamos acima, utilizamos a metodologia denominada pesquisaintervenção, que se aproxima e se fundamenta, em parte, na pesquisa-ação, por ser um trabalho tradicionalmente realizado por pesquisadores implicados no sentido dado por Barbier (2007). O pesquisador implicado busca caminhos para concretizar mudanças necessárias ao bom funcionamento da instituição, envolvendo os participantes diretamente no debate sobre o tema.

A pesquisa-ação visa mudanças e resoluções de problemas, pressupondo uma ação coletiva entre os participantes do processo investigativo/interventivo. A relação com o meio é interativa desprovida de circunstância pré-fabricadas ou de definições concebidas a priori (Miranda, 2012, p. 15).

Ser professora, pesquisadora, militante do Movimento Social Negro e conhecer a situação educacional das crianças negras foi determinante para optar pela intervenção, e não por uma pesquisa tradicional que compreendesse apenas análises estatísticas, questionários e outros instrumentos afins, que pudessem distanciar ou dificultar o diálogo com a escola. A pesquisa-intervenção contraria a racionalidade iluminista, a neutralidade, a postura apolítica. Sua perspectiva central é o comprometimento com as mudanças comunitárias e institucionais.

Os institucionalistas pretendem que a ciência contribua não só com o espaço acadêmico, mas principalmente com as demandas sociais e com as práticas reais que se efetuam e a tem como sustentação. Nesta conjuntura um árduo esforço tem sido travado para elevar as pesquisas participativas a um status científico e para quebrar a hegemonia das pesquisas tradicionais vigentes (Romagnoli, 2014, p. 45).

Em acordo com a Secretaria de Educação de Ilhéus, trabalhamos com uma amostra composta por oito escolas, das 32 existentes, na época. Foi tarefa dos discentes descrever e avaliar a arquitetura das escolas, mas os dados de todas as escolas foram discutidos por todos os participantes da pesquisa, incluindo alguns gestores. Nessa perspectiva, o croqui e as fotos se tornaram fundamentais.

A primeira dificuldade surgiu no campo administrativo. Foi difícil conseguir uma lista completa das escolas, suas localizações, número exato de alunos e outras 
informações pertinentes. Esses dados não estavam devidamente registrados nem sistematizados, conforme argumento dos funcionários, em decorrência das constantes substituições do corpo administrativo cujos membros, habitualmente, são escolhidos por indicação política. A segunda dificuldade foi convencer as diretoras e as coordenadoras, não propriamente sobre a importância da pesquisa, mas da relevância do tema para a Educação Infantil e para a política educacional daquela região.

As primeiras visitas às escolas foram realizadas exclusivamente pelas coordenadoras da pesquisa. Aproveitamos, assim, o momento para iniciar junto com as gestoras das escolas algumas reflexões sobre a importância da arquitetura escolar tanto para o afeto como para o processo de aprendizagem, mesmo concordando que a mudança do espaço escolar não mude concomitante à prática pedagógica. Entretanto, como argumenta Gonçalves (1999, p. 48),

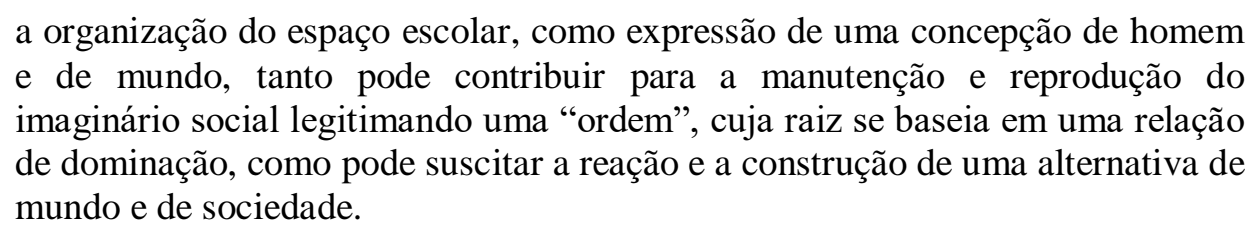

No segundo momento, incluímos os discentes para iniciar a tarefa de descrever a situação das escolas e fotografar os ambientes. Inicialmente, talvez por falta de conhecimento sobre legislações específicas e de outras leituras sobre o tema, os relatos foram bastante tímidos e consensuais, ou seja, parecia que tudo estava no seu devido lugar. Apareceram algumas críticas sobre a organização dos espaços, mas os problemas relacionados à arquitetura escolar pareciam ter ficado imperceptíveis. Entretanto, no decorrer do processo, com o avanço dos estudos, a postura do grupo foi mudando, notadamente, à medida que conseguiram perceber a arquitetura como um direito e sua necessidade para a concretização do projeto pedagógico. Gonçalves (1999, p. 48) afirma que "a ausência de vínculos mais estreitos entre a pedagogia e a arquitetura subtrai de seus usuários a faculdade de perceber as determinações, as possibilidades e o limites que a arquitetura coloca para a sua prática”.

Iniciamos nossos estudos a partir da leitura das Diretrizes Curriculares Nacionais Educação Básica- Educação Infantil (Brasil, 2001, p. 32), analisando 
especialmente a alínea $\mathrm{C}$ do item 4 , que se refere a organização dos espaços físicos e recursos materiais para a Educação Infantil:

Os espaços internos e externos deverão atender às diferentes funções da instituição de Educação Infantil, contemplando:

- ventilação, temperatura, iluminação, tamanho suficiente, mobiliário e equipamento adequados;

- instalações e equipamentos para o preparo de alimentos que atendam às exigências de nutrição, saúde, higiene e segurança, no caso de oferecimento de refeição;

- instalações sanitárias suficientes e próprias para uso exclusivo das crianças;

- local para repouso individual, pelo menos para crianças com até um ano de idade, área livre para movimentação das crianças, locais para amamentação e higienização e espaço para tomar sol e brincadeiras ao ar livre;

- brinquedos e materiais pedagógicos para espaços externos e internos dispostos de modo que garantam a segurança e a autonomia da criança e como suporte de outras ações intencionais.

Em seguida, passamos para a leitura dos Parâmetros Nacionais de Qualidade para a Educação Infantil (PQEI) (Brasil, 2006b) e dos Parâmetros Básicos de Infraestrutura para Instituições de Educação Infantil (PBIIEI) (Brasil, 2006a), que foram elaborados pelo MEC com objetivo de dar suporte legal, pedagógico e administrativo à construção de espaços educacionais para crianças de 0 a 6 anos.

Foram extremamente proveitosos as leituras e os debates sobre as funções específicas das Secretarias Municipais da Educação, conforme registrado nos Parâmetros Nacionais de Qualidade para a Educação Infantil. Naquele momento, observamos que o município de Ilhéus, por diferentes razões, muitas desconhecidas, estava extremamente distante das exigências legais. O que está registrado nos PBIIEI, no item intitulado "Um pouco de História", parecia se encaixar de modo exclusivo às escolas investigadas:

A história de atendimento à criança em idade anterior à escolaridade obrigatória foi marcada, em grande parte, por ações que priorizaram a guarda das crianças. Em geral, a Educação Infantil, e em particular as creches, destinava-se ao atendimento de crianças pobres e organizava-se com base na lógica da pobreza, isto é, os serviços prestados — seja pelo poder público seja por entidades religiosas e filantrópicas - não eram considerados um direito das crianças e de 
suas famílias, mas sim uma doação, que se fazia - e muitas vezes ainda se faz — sem grandes investimentos (Brasil, 2006a, p. 9).

Foi com base na leitura dos documentos citados acima que elaboramos um instrumento de avaliação muito simples, mas que possibilitou que as discentes observassem os espaços educacionais com muita propriedade e os comparasse às exigências legais.

Dessa forma, seguindo os critérios determinados pelos Referenciais Nacionais de Educação Infantil, escolhemos 12 itens, que destacamos a seguir, para serem analisados quanto à organização e ao funcionamento: 1) acesso; 2) arquitetura que incluía a forma de distribuição dos espaços e a conservação geral dos prédios; 3 ) mobília; 4) cozinha; 5) espaço da merenda; 6) banheiro; 7) espaço para brincar; 8) rede de água e esgoto; 9) brinquedos; 10) iluminação; 11) segurança; e 12) ventilação. Esses itens foram classificados como a) ótimo; b) bom; c) insatisfatório; d) ruim; e e) péssimo, conforme orientação descrita na ficha de avaliação destacada a seguir. 
Quadro 1 - Mapa de infraestrutura das escolas.

\begin{tabular}{|c|c|c|c|c|c|c|c|c|c|c|c|c|c|c|c|c|c|c|}
\hline ESCO & & & & & & & & & EN & DEREÇ & & & & & & & & \\
\hline $\begin{array}{l}\text { Acess } \\
1\end{array}$ & $\begin{array}{l}\text { Cons } \\
2\end{array}$ & $\begin{array}{l}\text { Móbil } \\
3\end{array}$ & $\begin{array}{l}\text { Cozin } \\
4\end{array}$ & $\begin{array}{l}\text { Meren } \\
5\end{array}$ & $\begin{array}{l}\text { Banh } \\
6\end{array}$ & $\begin{array}{l}\text { Brin } \\
7\end{array}$ & $\begin{array}{l}\text { Lazer } \\
8\end{array}$ & $\begin{array}{l}\text { Ilumin } \\
9\end{array}$ & $\begin{array}{l}\text { Venti } \\
10\end{array}$ & $\begin{array}{l}\text { Bibl } \\
\mathrm{i} \\
11\end{array}$ & $\begin{array}{l}\text { Labor } \\
\text { C } \\
12\end{array}$ & $\begin{array}{l}\text { LabIn } \\
\mathrm{f} \\
13\end{array}$ & \begin{tabular}{|l} 
Secr \\
$\mathrm{t}$ \\
14
\end{tabular} & \begin{tabular}{|l} 
Sal \\
a \\
Pro \\
f 15
\end{tabular} & $\begin{array}{l}\text { Segu } \\
\mathrm{r} \\
16\end{array}$ & $\begin{array}{ll}\mathrm{T} \\
\mathrm{V}\end{array}$ & Out & $\begin{array}{l}\text { observaçõe } \\
\text { s }\end{array}$ \\
\hline
\end{tabular}

1) Acesso; 2) Construção; 3 ) Mobília (armários, carteiras); 4) Cozinha (armários, geladeiras, panelas); 5) Merenda (elaboração da merenda); 6) Banheiro (pias, vasos sanitários, torneiras); 7) Espaço para brincadeira e quantidade/qualidade dos brinquedos (no caso de Educação Infantil); 8) Espaço para lazer (quadras e espaços para brincadeira no horário de recreio); 9) Iluminação; 10) Ventilação; 11) Biblioteca; 12) Laboratório de Ciências; 13) Laboratório de Informática; 14) Espaço de Secretaria da escola; 15) Sala de professores; 16) Condições de segurança (corrimão, piso, escadas, acesso para portadores de necessidades especiais e outros); e 17) Tecnologia (TV/DVD/SOM) — observar condições de uso e acesso; 18) outros.

Avaliação: Ótimo (O) em perfeitas condições; Bom (B) problemas que não afetam, imediatamente, a qualidade da escola, mas que precisam mudar (por exemplo, a pintura); Insatisfatório (I) afeta a estrutura da escola, mas não a qualidade de vida e o ensino; Ruim (R) coloca em risco a segurança dos alunos e a qualidade do ensino; Péssimo $(\mathrm{P})$ alunos e professores estão em completo risco de segurança e sem condições de boa qualidade de ensino.

Colocar X quando não houver o equipamento acima.

Revista da ABPN •v. 11, Ed. Especial - Caderno Temático: Raça Negra e Educação 30 anos depois: e agora, do que mais precisamos falar? • abril de 2019, p.101-125

DOI 10.31418/2177-2770.2019.v11.c.1.p101-125 
Como citamos anteriormente, fotografamos todos os espaços e elaboramos o croqui das escolas. Destacamos que cerca de $85 \%$ delas não tinham quaisquer documentos que se referissem à organização física dos espaços. Nesse sentido, pudemos oferecer, naquele momento, um instrumento, o croqui, muito valioso para as escolas. Os resultados dessa experiência, obviamente, não se comparam aos produzidos por instituições de pesquisa formal, justamente porque nossos objetivos diferem.

Nossa intervenção causou impactos positivos e negativos. Os negativos vieram como respostas das pessoas que consideravam nosso trabalho invasivo, meramente político e que expunha demasiadamente os problemas da região. Mas os resultados positivos foram muito profícuos; por exemplo, a arquitetura escolar já se tornou problema de pesquisa na universidade, os estagiários de Pedagogia já registram com detalhes a condição dos espaços destinados à Educação Infantil e atualmente temos uma disciplina intitulada "Gestão dos Espaços Públicos e Relação com a Comunidade" no currículo do Mestrado Profissional em Educação.

Por cinco anos, do segundo semestre de 2007 até o final de 2012, acompanhamos as possíveis mudanças na configuração dos espaços de Educação Infantil do município de Ilhéus, sem conseguir registrar qualquer mudança significativa que alterasse o quadro abaixo.

Tabela 1. Infraestrutura dos espaços de Educação Infantil municipal de Ilhéus BA. Diagnóstico preliminar (2007-2012)

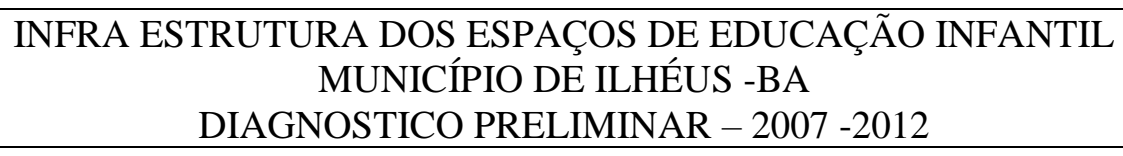

\begin{tabular}{|c|c|c|c|c|c|c|c|c|c|c|c|c|c|}
\hline & Escolas & $\begin{array}{l}\text { Aces } \\
\text { so }\end{array}$ & Const. & Mob. & Coz. & $\begin{array}{l}\text { Es } \\
\text { Mer } \\
\end{array}$ & Ban & E.brin & Agua & brinq & Ilum & Seg. & Ven \\
\hline 1 & Andorinha & I & $\mathrm{B}$ & $\mathrm{B}$ & B & $\mathrm{B}$ & B & $\mathrm{O}$ & B & B & B & B & B \\
\hline 2 & Pardal & $\mathrm{P}$ & P & $\mathrm{P}$ & $\mathrm{P}$ & P & $\mathrm{R}$ & $\mathrm{P}$ & $\mathrm{R}$ & $\mathrm{R}$ & $\mathrm{R}$ & $\mathrm{R}$ & $\mathrm{R}$ \\
\hline 3 & Canário & $\mathrm{R}$ & $\mathrm{R}$ & $\mathrm{R}$ & $\mathrm{R}$ & $\mathrm{R}$ & $\mathrm{R}$ & $\mathrm{R}$ & $\mathrm{R}$ & $\mathrm{R}$ & $\mathrm{R}$ & $\mathrm{R}$ & $\mathrm{R}$ \\
\hline 4 & Bem-te-vi & $\mathrm{P}$ & $\mathrm{P}$ & $\mathrm{P}$ & $\mathrm{P}$ & $\mathrm{P}$ & $\mathrm{P}$ & $\mathrm{P}$ & $\mathrm{P}$ & $\mathrm{P}$ & I & $\mathrm{P}$ & I \\
\hline 5 & Periquito & $\mathrm{R}$ & I & $\mathrm{R}$ & $\mathrm{R}$ & $\mathrm{R}$ & $\mathrm{R}$ & $\mathrm{R}$ & $\mathrm{R}$ & $\mathrm{R}$ & $\mathrm{R}$ & $\mathrm{R}$ & I \\
\hline 6 & Sabiá & $\mathrm{B}$ & I & B & B & B & B & I & B & $\mathrm{R}$ & $\mathrm{B}$ & B & B \\
\hline 7 & Pintassilgo & $\mathrm{B}$ & $\mathrm{B}$ & B & $\mathrm{B}$ & $\mathrm{R}$ & I & I & $\mathrm{B}$ & I & $\mathrm{B}$ & $\mathrm{B}$ & $\mathrm{B}$ \\
\hline 8 & Curió & B & I & I & B & $\mathrm{R}$ & $\mathrm{R}$ & I & B & B & $\mathrm{R}$ & B & $\mathrm{R}$ \\
\hline 9 & Tico- tico* & & & & & & & & & & & & \\
\hline
\end{tabular}

Fonte: Dados da pesquisa.

Revista da ABPN • v. 11, Ed. Especial - Caderno Temático: Raça Negra e Educação 30 anos depois: e agora, do que mais precisamos falar? • abril de 2019, p.101-125 
Nessa tabela, apenas a avaliação de um dos ambientes, localizado na escola Andorinha, que se refere ao espaço de brincadeira, pode ser considerada ótima. Vale ressaltar que a referida escola foi construída pelo Ministério de Educação (MEC).

Entre as oito escolas avaliadas, apenas duas foram classificadas como de bom estado no item que se refere à construção, entretanto a arquitetura não estava e ainda não está compatível com a legislação. Três escolas foram classificadas como insatisfatórias, uma classificada como ruim e duas como péssimas, isto é, não tinham quaisquer condições para abrigar as crianças pequenas.

As cozinhas de quatro escolas foram consideradas péssimas e ruins. Apenas duas escolas apresentaram espaços adequados para a distribuição de merenda, e seis não possuíam espaço para a distribuição de merenda.

A qualidade da água, a iluminação e a segurança foram consideradas ruins e péssimas, sendo que quatro escolas apresentaram todos os itens vermelhos, desde a arquitetura, passando pela ventilação, espaço para merenda, banheiros e os demais itens.

No aspecto arquitetônico, nenhuma construção foi considerada ótima pelo grupo de pesquisa que coletou e analisou os dados. Em termos de porcentagem, apenas $25 \%$ foram avaliadas como boa, as outras, equivalentes a $75 \%$, foram classificadas como ruins e péssimas. Ressaltamos que "Bom" não significa estar dentro das normas dos Parâmetros Básicos de Infra-estrutura para Instituições de Educação Infantil (BRASIL, 2006a). Nesse caso, apenas uma escola, a Andorinha, estava em situação regular, naquele momento.

Essa tabela, como já citamos, foi construída coletivamente; as equipes trouxeram fotos das escolas com destaque de todos os ambientes e foram apresentando suas justificativas de avaliação durante as reuniões de estudo. Nos anos de 2009, 2010, 2011 e 2012, outros grupos de discentes voltaram às escolas para registrar possíveis modificações. Nesse intervalo, travamos uma batalha difícil com os administradores do município, primeiro porque não houve, nessas instituições, quaisquer mudanças positivas. Segundo, porque escrevemos artigos e apresentamos os resultados das pesquisas em reuniões e eventos que ocorriam na região. 
Nesses momentos, a naturalização sobre a precariedade do espaço escolar ficava evidente; por exemplo, em uma das vezes que apresentamos o quadro de avaliação, uma diretora argumentou que, apesar dos problemas estruturais, a instituição que dirigia era um presente para aquelas crianças extremamente pobres, porque a condição da casa delas era muito pior. "Enquanto estão aquil", disse outra, "estão alimentadas e livres da violência e do tráfico de drogas". Nessa perspectiva, concluímos que o espaço de Educação Infantil funcionava apenas como um abrigo para as crianças pequenas, tendo em vista a saída das mães para o trabalho e a pobreza da região. A distribuição da merenda, por vezes, aparecia como questão central, encobrindo o objetivo de cuidar e educar, conforme a orientação legal.

O argumento sobre a importância da arquitetura era refutado por discursos de teor conformistas e baseado no mérito. Nesse contexto, o amor e a caridade eram exaltados, notadamente nas escolas administradas por grupos religiosos, destacando os seguintes comentários: "não importa o prédio, quando o aluno se esforça, consegue vencer", "com fé e persistência a gente consegue tudo", "aqui todo mundo é pobre e tem mesmo que lutar".

Em meio ao calor insuportável, salas de aulas apertadíssimas, sem a mínima ventilação, sem espaço para lanche e brincadeiras, algumas educadoras ainda pareciam convencidas de que aqueles problemas eram perfeitamente contornáveis quando se trabalha com dedicação, amor e fé em Deus.

Com essa postura, tais educadoras assumiam para si a responsabilidade pelo bem-estar das crianças e pela preservação da arquitetura da escola, que pesavam sobre os ombros daquelas mulheres também vítimas da falta de políticas públicas.

Outro ponto inerente ao processo de investigação foi o pertencimento étnicoracial. Dialogamos com as gestoras sobre esse tema, pedindo uma porcentagem aproximada dos alunos que ela considerava negros, conforme a classificação do Instituto Brasileiro de Geografia e Estatística (IBGE). A primeira diretora questionada, da Escola Bem-Te-Vi, disse que, conforme seu olhar, sua escola era composta por $80 \%$ de alunos negros. A referida instituição está localizada em um bairro cuja arquitetura expressa um alto grau de miséria e abandono. A diretora responsável pela escola Sabiá 
disse que, na sua instituição, os negros se aproximavam de 85\%. Quando visitei tal escola, parecia que estava dentro de um quilombo. Naquela escola são negros professores, alunos, vigias e merendeiras, a linha de cor muda para o tom de pele, um pouco mais clara, apenas no espaço da diretoria. Julgo importante ressaltar que o estado da Bahia é considerado nacional e internacionalmente Território Negro, por abrigar várias instituições e espaços culturais vinculados à cultura africana.

De modo geral, as gestoras afirmaram que as suas instituições atendiam majoritariamente alunos negros, calculando uma margem de $80 \%$ a $90 \%$. Mas algumas ficaram em dúvida, e outras negaram veementemente nossa questão de pesquisa, que, por ora, retomamos: existem conexões entre arquitetura escolar, condição social dos usuários e a variável cor/etnia?

À época, alguns discentes que compunham o grupo de pesquisa também sentiram dificuldades em relacionar a precariedade das escolas ao preconceito étnicoracial. Mas os dados estatísticos sobre a situação educacional da população negra forneceram elementos para o início do debate, e posteriormente recorremos ao estudo de Célia Maria Marinho Azevedo (1987), intitulado Onda Negra, Medo Branco, e à obra de Jerry Dávila (2006), denominada Diploma de Brancura, que relata a política social e racial no Brasil, entre 1917 e 1945.

O Censo de 2000 (IBGE, 2003, p. 1) referente à corletnia e educação apontou que "5,8 milhões de brasileiros de 25 anos ou mais de idade tinham o curso superior concluído e que a proporção de brancos com este nível de ensino é 5 vezes maior que a de pretos, pardos indígenas".

E sobre a educação de crianças pequenas, o mesmo censo indicava que:

Entre o total de alfabetizados com 5 anos ou mais de idade (129,3 milhões), mais da metade é formada por pessoas que se declararam brancas $(56,8 \%)$, seguidas pelas pardas $(35,9 \%)$, pretas $(5,8 \%)$, amarelas $(0,5 \%)$ e indígenas $(0,4 \%)$. Em relação à população não-alfabetizada (24 milhões), $51,5 \%$ são pardos; $37,2 \%$, brancos; $9,5 \%$, pretos; $0,8 \%$, indígenas e $0,2 \%$, amarelos (IBGE, 2003, p. 6).

A análise de um conjunto de dados semelhantes aos apresentados acima possibilitou que, aos poucos, fôssemos enxergando o município de Ilhéus no contexto 
brasileiro de educação, e, mais à frente, com a introdução dos estudos de Azevedo (1987) e de Dávila (2006), consecutivamente, conseguimos fazer conexões entre relações étnico-raciais, questões regionais e a arquitetura das escolas.

Conforme estudos de Azevedo (1987) e Dávila (2006), o Nordeste, especialmente o estado da Bahia, ainda sofre os impactos negativos gerados pelo Projeto Imigrantista, que embalou os sonhos brancos da nação brasileira, no período pré-abolicionista. O imigrantismo foi o instrumento político e pseudocientífico utilizado pela elite brasileira com o objetivo de trocar a mão de obra negra pela branca estrangeira, mas havia outras finalidades intrínsecas, como a construção dos espaços urbanos, o branqueamento da população e o medo das revoltas negras, principalmente porque muitas já recebiam apoio popular.

Vale destacar os argumentos do marquês João Severiano Maciel da Costa, registrados em sua obra intitulada Memória sobre a Necessidade de Abolir a Introdução de Escravos Africanos no Brasil, publicada em 1821, que defendia a imigração de modo contundente, justificando que os negros não seriam capazes de participar da reconstrução do Brasil, por serem oriundos da África, considerado por ele um continente sem lei nem moral ${ }^{8}$. Sua voz representava, em parte, o temor da elite branca.

Diante da iminência de uma cisão entre o Norte e o Sul, ideia que se tornou popular nas duas regiões, o deputado Martim Francisco, da Assembleia Legislativa Provincial de São Paulo, expressou o seu medo, conforme argumenta Azevedo (1987, p. 106): "ao final desta exportação acelerada de negros, o Norte estaria livre, para formar um Estado separado, deixando o Sul em maus lençóis”, já que os escravos estavam sendo maciçamente trazidos para o Sul do país.

Ainda, conforme o estudioso acima citado, a preferência pelo branco estrangeiro era abertamente declarada nos espaços políticos e da mídia (Azevedo, 1987). A autora cita o exemplo do alagoano Aureliano Candido de Tavares Bastos, que defendia abertamente a abolição, entretanto, não era apenas pela defesa do negro, mas porque julgava que a escravidão só trazia prejuízo:

\footnotetext{
8 "Que faremos pois nós desta maioridade de população heterogênea incompatível com os brancos, antes inimiga declarada” (Da Costa, 1821 apud Azevedo, 2004, p. 33).
} 
E isto poderia ser melhor comprovado comparando-os ao atraso da Província da Bahia, onde vivia uma maioria de negros "grosseiros", ignorantes e incapazes para o trabalho, com o grande desenvolvimento do Rio Grande do Sul, com seus núcleos de colonos europeus, efervescentes em matéria de trabalho, progresso e civilização (Azevedo, 1987, p. 53).

Esse pensamento gerou estratégias políticas e econômicas de impedimento da vinda de negros do Norte para o Sul. Nessa perspectiva, os negros baianos, especificamente, ficaram confinados no espaço geográfico denominado Nordeste, sem possibilidades de sair e com péssimas condições para permanecer. Enquanto as regiões Sul e Sudeste foram intencionalmente povoadas pela população branca, que recebeu o apoio necessário para preservar sua cultura e usufruir todos os privilégios da modernidade.

Jerry Dávila (2006, p. 117) argumenta que, no contexto educacional, “as variações regionais importam mais do que qualquer outro fator”. Os fatos históricos indicam que, não por acaso, há décadas o Sul e o Sudeste apresentam resultados superiores ao desempenho do Norte e do Nordeste.

Em 1940, no Paraná, a alfabetização chegava a 45\%, enquanto no Distrito Federal atingia $77 \%$. Enquanto isso, como era típico no Norte, a alfabetização da Bahia era apenas $21 \%$, e no Rio Grande do Norte era apenas ligeiramente superior a $27 \%$, a baixa taxa de alfabetização era sintomática das maiores limitações da pública no Norte e Nordeste do Brasil. Em 1944, os estados do Sul gastaram anualmente quase $\mathrm{Cr} \$ 23$ por habitantes na educação (acima da média nacional de $\mathrm{Cr} \$ 15)$. Enquanto isso, os estados do Nordeste gastaram em média menos de $\mathrm{Cr} \$ 6$. Os dois sistemas escolares que gastavam mais em educação per capita eram o de São Paulo, com Cr\$33, e o Distrito Federal, com Cr\$ 67 (Dávila, 2006, p. 117).

Ainda conforme Dávila (2006, p. 122) "na Bahia, onde menos de um terço da população se identificava como branca no Censo de 1940, tinha um sistema escolar que alcançava menos de uma em cada seis crianças”. São os estados com maior concentração de população negra e indígena que apresentam as mais baixas taxas de investimentos.

Pesquisas mais recentes, notadamente as desenvolvidas por órgãos governamentais, confirmam as consequências históricas forjadas pela exclusão regional. Por exemplo, o Plano Nacional de Educação, elaborado em 2000, informou que o Nordeste tinha as piores condições de infraestrutura escolar. 
Em relação à infraestrutura dos estabelecimentos, relativamente a 1998, há que se apontar que 4.153 pré-escolas, que atendem a 69.714 crianças, não têm abastecimento de água, $84 \%$ das quais se situam no Nordeste. Essa carência ocorre para menos de $0,5 \%$ das crianças atendidas nas regiões Sudeste, Sul e Centro-Oeste. Além disso, $70 \%$ dos estabelecimentos não têm parque infantil, estando privados da rica atividade nesses ambientes nada menos que 54\% das crianças. É possível que muitos dos estabelecimentos sejam anexos a escolas urbanas de ensino fundamental, onde o espaço externo é restrito e tem que ser dividido com muitos outros alunos (Brasil, 2001, p. 09).

Tabela 2. Percentual das escolas da Educação Básica com todos os itens de estrutura adequada.

\begin{tabular}{|l|c|c|c|c|c|}
\hline Região & 2009 & 2010 & 2011 & 2012 & 2013 \\
\hline Brasil & 3,06 & 3,41 & 3,93 & 4,18 & 4,19 \\
\hline Norte & 0,26 & 0,37 & 0,39 & 0,41 & 0,45 \\
\hline Nordeste & 0,73 & 1,02 & 1,11 & 1,32 & 1,30 \\
\hline Sudeste & 6,72 & 7,00 & 8,64 & 8,70 & 8,40 \\
\hline Sul & 7,01 & 7,89 & 7,90 & 8,69 & 8,83 \\
\hline Centro-Oeste & 2,77 & 3,02 & 3,24 & 3,50 & 3,02 \\
\hline
\end{tabular}

Fonte: Menos (2014, s/p).

É possível encontrarmos conexões entre as informações que compõem o quadro de situação dos espaços de Educação Infantil do município de Ilhéus e os apresentados na tabela acima, embora um seja avaliativo e não numérico e o outro, produzido pelo INEP (2017), apresente informações estatísticas. Mas ambos revelam o descumprimento das legislações referentes à arquitetura escolar, o que implica humilhação e falta de respeito ao ser humano. Revelam também a inércia governamental: no espaço de quatro anos quase nada mudou, particularmente em Ilhéus e no Brasil, em relação à construção de escolas. E, embora as regiões Sul e Sudeste estejam historicamente à frente, como nos outros quesitos educacionais, seus desempenhos são extremamente fracos, inferiores a $10 \%$.

As pesquisas mais recentes indicam que a infraestrutura é um problema que se tornou praticamente invisível, sem importância em todas as regiões, independentemente do resultado do Produto Interno Bruto (PIB). Esse fato parece quase não incomodar grande parte dos sindicatos e fóruns permanentes de educação. A questão se apresenta como natural.

O Sul e o Sudeste foram os que mais ampliaram o percentual de escolas com infraestrutura adequada, e são os que têm as maiores taxas, $8,83 \%$ e $8,40 \%$, 
respectivamente. A Região Centro-Oeste tem uma diferença de quase 5 pontos a menos das anteriormente citadas, com 3,92\% das escolas com todos os itens. Já as Regiões Norte e Nordeste tiveram a menor taxa de escolas com as condições exigidas (Menos, 2014, s/p).

Naturalizar, em princípio, é interpretar as questões históricas como um fenômeno natural, sem perceber que as desigualdades étnico-raciais, de gênero e outras foram historicamente construídas e podem ser desconstruídas, ao menos que se acredite que tudo está no seu devido lugar ou que há uma ordem "superior" que determina o lugar de cada um. Nesses casos não há o que se fazer. Cada grupo frequentará a escola que lhe foi "predestinada".

A naturalização é um processo do pensamento, bastante comum nas representações cotidianas e no mundo da ideologia. Este é um interesse da classe dominante, que quer naturalizar a exploração, a dominação e as formas de opressão. Porém, a naturalização não é um puro produto do pensamento. Eis a questão que muitos se esquecem. Só é possível naturalizar o que existe (Viana, 2013, p. 73).

\section{CONCLUINDO}

Como já citamos, passamos do segundo semestre de 2007 ao final de 2012 observando a arquitetura das escolas pesquisadas, sem conseguir alterar o registro inicial. Entretanto, o debate sobre o tema foi se tornando cada vez mais importante na região, chegando a incomodar um grupo de promotores que organizaram uma equipe para visitar escolas que estavam em situação de risco.

No final de 2012, tivemos que suspender temporariamente a pesquisa para desenvolver outros projetos, principalmente para ajudar na implantação do Mestrado em Educação Profissional, no qual, como citamos, conseguimos introduzir duas disciplinas relacionadas às políticas públicas; em uma delas, intitulada "Gestão dos Espaços Públicos e relação com a comunidade", incluímos o estudo da arquitetura escolar. Esse foi um dos melhores resultados que obtivemos, somados ao envolvimento da comunidade.

No primeiro semestre de 2017, fui convidada para ministrar um curso sobre relações étnico-raciais na Educação Infantil para professores do município de Ilhéus. Aproveitei a oportunidade e inseri a arquitetura escolar como um dos temas a serem colocados em questão. Nessa perspectiva, solicitei que os participantes levassem 
fotografias de todos os espaços da escola, destacando o acesso à instituição e à organização de todos os ambientes e que também providenciassem imagens dos alunos desenvolvendo atividades.

Trabalhamos com dois grupos de 30 professores, em momentos diferentes, com o objetivo de analisar a arquitetura escolar com base em três questionamentos: 1) A arquitetura escolar pode revelar desigualdades regionais? 2) A arquitetura escolar pode expressar o preconceito étnico-racial? 3) A arquitetura escolar influencia a aprendizagem?

O primeiro e o segundo grupo foram unânimes em afirmar que a arquitetura escolar revela desigualdades regionais, mas tivemos que aprofundar o conceito de desigualdades e o de diferença. Em relação à segunda questão, os participantes negaram e colocaram em dúvida o vínculo entre arquitetura e preconceito étnico-racial; apenas duas professoras do primeiro grupo afirmaram categoricamente, sendo que uma delas argumentou "que a escola daquele lugar (Ilhéus) tem cheiro e cor. Quanto mais negros são os alunos, pior é o prédio, mais sem cuidado e o cheiro de esgoto é sentido de longe". O grupo foi unânime em afirmar que a arquitetura escolar influencia a aprendizagem.

No decorrer do processo de formação, fomos analisando as fotografias de cada prédio, a organização dos espaços e a cor das crianças e concluindo que o conjunto das escolas ali apresentadas, por diferentes motivos, não correspondiam às orientações dos Parâmetros Básicos de Infra-estrutura para as Instituições de Educação Infantil (BRASIL, 2006a). Nessa direção, foi possível observar que algumas instituições funcionam com banheiros sem portas e com vasos sanitários padronizados para adultos. Os espaços para brincar são praticamente inexistentes ou minúsculos.

Ainda dentro desse quadro, observamos que as escolas de periferia estavam em piores condições, e que, nessas escolas, a presença das crianças negras era marcante, conforme indicou os estudos de Rosemberg (1987).

As professoras aproveitaram o momento para compartilhar suas angústias em relação à arquitetura e à configuração dos espaços que limitavam suas ações e impediam 
o desenvolvimento dos projetos pedagógicos. A coordenadora de Educação Infantil do município, que acompanhou o trabalho que ocorreu no período de 2007 a 2012, também estava presente no processo de formação e nos informou que as condições das escolas continuavam as mesmas, nada havia mudado. No quadro geral, as crianças pequenas estavam distribuídas em 32 unidades, sendo que apenas duas correspondiam aos padrões, mas uma estava completamente deteriorada, e o acesso da outra era feito exclusivamente por escadas.

Finalizamos este artigo reforçando que a nossa proposta, desde o início, tem sido colocar o tema em evidência no município, dando subsídios para que as professoras e a comunidade possam detectar as desigualdades e preconceitos vinculados à arquitetura escolar. Entretanto, divulgar os resultados e publicar artigos também é uma forma de contribuir para o combate a todas as formas de discriminação.

E agora? Ainda temos que continuar denunciando o preconceito étnico-racial nas diferentes áreas de conhecimento, seja por meio de pesquisas, relatos de experiências e outras modalidades de saber que contribuam para a melhoria de qualidade de vida do povo negro.

\section{REFERÊNCIAS}

AZEVEDO, Célia Maria Marinho de. Onda Negra, Medo Branco: o negro no imaginário das elites - século XIX. Rio de Janeiro: Paz e Terra, 1987.

BARBIER, René. A Pesquisa-ação. Tradução de Lucie Didio. Brasília: Liber Livro Editora, 2007.

BENCOSTTA, Marcus Levy Albino Educar. Arquitetura e Espaço Escolar: reflexões acerca do processo de implantação dos primeiros grupos escolares de Curitiba (1903-1928). Educar, Curitiba, n. 18, p. 103-141, 2001. Disponível em: <http://www.scielo.br/pdf/er/n18/n18a08.pdf>. Acesso em: 03 set. 2017.

BRASIL. Ministério da Educação. Diretrizes Curriculares Nacionais para a Educação das Relações Étnico-Raciais e para o Ensino de História e Cultura Afro-Brasileira e Africana. Brasília: MEC, 2004.

BRASIL. Lei $n^{\circ}$ 010172, de 9 de janeiro de 2001. Aprova o Plano Nacional de Educação e dá outras providências. Brasília, DF, 2001. Disponível em:< http://portal.mec.gov.br/arquivos/pdf/L10172.pdf>. Acesso em: 20 jul. 2018.

BRASIL. Ministério da Educação. Secretaria de Educação Básica. Parâmetros Básicos de Infra-estrutura para as Instituições de Educação Infantil. Brasília: MEC, SEB, 2006a.

Revista da ABPN • v. 11, Ed. Especial - Caderno Temático: Raça Negra e Educação 30 anos depois: e agora, do que mais precisamos falar? • abril de 2019, p.101-125 
BRASIL. Ministério da Educação. Secretaria de Educação Básica. Parâmetros Nacionais de Qualidade para a Educação Infantil. Brasília: MEC, SEB, $2006 \mathrm{~b}$.

BRASIL. Secretaria-Geral da Presidência da República. Secretaria Nacional de Juventude. Ministério da Justiça. Fórum Brasileiro de Segurança Pública. Índice de Vulnerabilidade Juvenil à Violência e Desigualdade Racial 2014. Brasília, DF: Presidência da República, 2015. (Série Juventude Viva). Disponível em: <http://unesdoc.unesco.org/images/0023/002329/232972POR.pdf.>. Acesso em: 27 set. 2017.

DÁVILA, Jerry. Diploma de Brancura: política social e racial no Brasil - 1917-1945. Tradução Claudia Santana Martins. São Paulo: Editora Unesp, 2006.

GONÇALVES, Rita de Cassia. A Arquitetura Escolar como Materialidade do Direito Desigual à Educação. Ponto de Vista, Florianópolis, v. 1, n. 1, p. 47-57, jul./dez. 1999. Disponível em: <https://periodicos.ufsc.br/index.php/pontodevista/article/view/1520/1529>. Acesso em: 27 set. 2017.

INSTITUTO EDUCACIONAL DE ESTUDOS E PESQUISAS EDUCACIONAIS ANÍSIO TEIXEIRA - INEP. Indicadores de Fluxo Escolar da Educação Básica. Brasília, DF: INEP, 2017.

INSTITUTO BRASILEIRO DE GEOGRAFIA E ESTATÍSTICA - IBGE. Censo Demográfico - 2000: Educação: Resultados da Amostra. IBGE, 2003. Disponível em: <https://ww2.ibge.gov.br/home/presidencia/noticias/pdf/02122003censoeduc.pdf >. Acesso em: 27 set. 2017 ,

MENOS de 5\% das Escolas tem Infraestrutura Adequada ao PNE. Todos pela Educação, São Paulo, 28 abr. 2014. Disponível em: <http://www.todospelaeducacao.org.br/reportagenstpe/30192/-2014>. Acesso em:

27 set. 2017.

MIRANDA. Maria Irene. Pesquisa-ação Escolar: uma tentativa de enfrentamento aos desafios educacionais. In: SILVA, Lazara Cristina; MIRANDA, Maria Irene (Org.). Pesquisa-ação uma alternativa à práxis educacional. Uberlândia: EDUF, 2012. p. 13-28.

NUNES, Clarice. Anísio Teixeira. Recife: Fundação Joaquim Nabuco; Editora Massangana, 2010. (Coleção Educadores).

OLIVEIRA, Rachel de. Reflexões sobre a Experiência de Alteração Curricular em São Paulo. Cadernos de Pesquisa, São Paulo, n. 63, p. 64-66, 1987.

ROMAGNOLI, Roberta Carvalho. O Conceito de Implicação e a Pesquisa de Intervenção Institucionalista. Psicologia e Sociedade, Belo Horizonte, v. 26, n. 1, p. 44-52, 2014. Disponível em: <http://www.scielo.br/pdf/psoc/v26n1/06.pdf>. Acesso em: 29 jul. 2018.

ROSEMBERG, Fúlvia. Relações Raciais e Rendimento Escolar. Cadernos de Pesquisa, São Paulo, n. 63, p. 19-23, 1987.

ROSEMBERG, Fúlvia et al. Diagnóstico sobre a Situação Educacional de Negros (Pretos e Pardos) no Estado de São Paulo. São Paulo: Fundação Carlos Chagas, 1986.

SANTOS, Milton. Por uma Geografia Nova. São Paulo: Hucitec, 1978.

Revista da ABPN • v. 11, Ed. Especial - Caderno Temático: Raça Negra e Educação 30 anos depois: e agora, do que mais precisamos falar? • abril de 2019, p.101-125

DOI 10.31418/2177-2770.2019.v11.c.1.p101-125 
TAVARES, Luís Henrique. Depoimento. In: ROCHA, João Augusto de Lima (Org.). Anísio em Movimento: a vida e as lutas de Anísio Teixeira pela Escola Pública e pela Cultura no Brasil. Brasília, DF: Senado Federal; Conselho Editorial, 2002. p. 161-168. (Coleção Biblioteca Básica Brasileira). Disponível

em <https://www2.senado.leg.br/bdsf/bitstream/handle/id/1060/619664.pdf?sequence=4>. Acesso em: 25 set. 2017.

VIANA, Nildo. Naturalização e desnaturalização: o dilema da negação prático-crítica. Revista Espaço Livre, [S.1], v. 8, n. 15, p. 72-81, jan./jun. 2013. 